SUPPLEMENT

\title{
Biomechanical investigation of head impacts in football
}

\author{
C Withnall, N Shewchenko, R Gittens, J Dvorak
}

Br J Sports Med 2005;39(Suppl I):i49-i57. doi: 10.1136/bjsm.2005.019182

\begin{abstract}
Objectives: This study sought to measure the head accelerations induced from upper extremity to head and head to head impact during the game of football and relate this to the risk of mild traumatic brain injury using the Head Impact Power (HIP) index. Furthermore, measurement of upper neck forces and torques will indicate the potential for serious neck injury. More stringent rules or punitive sanctions may be warranted for intentional impact by the upper extremity or head during game play.

Methods: Game video of 62 cases of head impact (38\% caused by the upper extremity and 30\% by the head of the opposing player) was provided by F-MARC. Video analysis revealed the typical impact configurations and representative impact speeds. Upper extremity impacts of elbow strike and lateral hand strike were re-enacted in the laboratory by five volunteer football players striking an instrumented Hybrid III pedestrian model crash test manikin. Head to head impacts were re-enacted using two instrumented test manikins. Results: Elbow to head impacts $(1.7-4.6 \mathrm{~m} / \mathrm{s})$ and lateral hand strikes $(5.2-9.3 \mathrm{~m} / \mathrm{s})$ resulted in low risk of concussion $(<5 \%)$ and severe neck injury $(<5 \%)$. Head to head impacts $(1.5-3.0 \mathrm{~m} / \mathrm{s})$ resulted in high concussion risk (up to $67 \%$ ) but low risk of severe neck injury $(<5 \%$ ).

Conclusion: The laboratory simulations suggest little risk of concussion based on head accelerations and maximum HIP. There is no biomechanical justification for harsher penalties in this regard. However, deliberate use of the head to impact another player's head poses a high risk of concussion, and justifies a harsher position by regulatory bodies. In either case the risk of serious neck injury is very low.
\end{abstract}

See end of article for authors' affiliations Correspondence to:
C Withnall, Biokinetics and Associates Ltd, Ontario, Canada; withnall@ biokinetics.com

$\mathrm{H}$ ead injury is reported to account for up to $22 \%$ of all injuries in football, although this includes all severities of injury and the injury mechanisms are not well documented. ${ }^{12}$ The intentional use of the head to strike the ball has been linked to cognitive deficit in some studies, ${ }^{3-6}$ but others have found this evidence inconclusive and potentially caused by older generation balls that became heavy when wet. $^{7-9}$ When one thinks of head impact in football, the ball is a natural first thought. But Kirkendall et $a l^{2}$ suggested that injurious head impact most often occurs when players compete for airballs. Boden et al ${ }^{10}$ studied 29 football concussions among 26 college players over two years. None were caused by heading the ball, $28 \%$ from contact with the opposing player's head, 14\% from elbow contact, and the remainder from impact with the ball $(24 \%)$, ground $(10 \%)$, lower extremities $(6 \%)$, or other structures. Barnes et al ${ }^{11}$ studied 102 concussions among 144 male and female players at a US tournament festival, and reported $68 \%$ of concussions resulting from collision with another player. They further stated that many of these occurred during the act of heading.

Andersen et al $^{12}$ studied 192 incidents of head impact in video recordings of Norwegian and Icelandic professional matches. The commonest playing action was a heading duel $(58 \%)$, and contact was with the upper extremity in $43 \%$ of cases and by the head in $32 \%$ of cases. Of the upper extremity hits $(n=83)$, active elbow use was observed in 61 cases $(73 \%)$, and the referee declared no foul in 53 cases $(64 \%)$. Of the head strikes $(n=62)$ the impact was to the back of the head $(35 \%)$, face $(31 \%)$, side $(24 \%)$, and forehead $(10 \%)$, and the referee declared no foul in 44 cases $(71 \%)$. Only one concussion was reported from upper extremity impact, and one from head to head impact.

Recently Fuller et al ${ }^{13}$ studied 163 video cases of head/neck injuries sustained in 20 Fédération Internationale de Football Association (FIFA) tournaments between 1998 and 2004. Concussion was diagnosed in $11 \%$ of cases. The commonest cause was an aerial challenge (55\%) in which head impact

was with the challenging player's upper extremity (33\%) or head $(30 \%)$. The authors stated that the unfair use of the upper extremity was significantly more likely to cause an injury than any other player action, but that the majority of challenges investigated were within the laws of the game. Fuller $e$ al $^{14}$ also analysed videos of 123 international matches and 8572 tackles to investigate the frequency of football injury. They commented that vertical jumping tackles involving the clash of heads presented a high injury risk. Of 23 such cases reviewed, 18 were declared no foul (78\%), but $15(65 \%)$ required medical attention.

Players competing for jump balls will obviously aim to gain all advantage. The use of elbows and arms to win the battle for space is a well known strategy to protect oneself and dissuade others from challenging the header. Head to head impact may occur as an unfortunate side effect of a good challenge, or it might be used intentionally to intimidate an opponent. In a recent study of football referees' decisions in incidents involving injury, Fuller et $a l^{15}$ found that for head injury, the on-field referee's call was generally reliable within the laws of the game.

From these data, the following inference might be made: if most head injuries occur in aerial challenges from upper extremity and head contact, if $64-78 \%$ of these are called legal, and if the referees' calls are accurate, then it implies we find a good portion of head injuries acceptable. While it is clearly the desire to reduce head injury in football, this argument implies a case for stricter interpretation of the rules, harsher penalties, and/or rule changes to discourage the use of these dangerous tactics.

The clinical investigations cited above provide valuable information about the frequency and circumstances of head impacts and head injuries. However, literature on identifying the biomechanical parameters associated with upper extremity and head to head impact is lacking. These include the typical impact speeds, energies, and resulting head accelerations levels. Video analysis has been developed and applied in 
football over many years. It use has been demonstrated in a range of applications, such as the impact of ground layout on players' safety, assessment of player tackles, and injury mechanisms. ${ }^{16-20}$ Video analyses of American football collisions, and laboratory re-enactments of these collisions using automotive crash test manikins, have yielded injury functions relating linear and angular head accelerations with the risk of concussion. ${ }^{21} 22$

Our aim in the current study was to conduct a similar biomechanical analysis of upper extremity and head to head impact of football players and re-enact these events in the laboratory to assess the risk of concussion. The risk of serious neck injury was also investigated. Careful consideration of both the clinical and biomechanical aspects of head impact will allow regulators of the game to make informed decisions about the rule changes, penalties, and sanctions for inappropriate play.

\section{METHODS}

We obtained game video of 62 cases of head impact in FIFA sanctioned matches from the FIFA Medical Assessment and Research Centre (F-MARC), Switerland. We analysed the videos to identify and quantify the various categories of contact. The cases were recorded from regular broadcast media. Various camera angles had been employed during the broadcast of the matches, which provided multiple views for many events and a single view for other events. The various views included close-ups and distant as well as elevated and field-level views of the incidences. Due to the variations in camera distance and elevation some video clips were of use for further analysis while others were found not useful because of the image quality and number of views provided.

The categories of impact included head, upper extremity, knee, ball, and foot. The relative frequencies of these impacts is shown in fig 1 . On the basis of this sample of video clips, the head impacts were $38 \%$ from the upper extremity and $30 \%$ from another head, similar to Andersen et al's findings ${ }^{12}$ (43\% upper extremity and 32\% head).

\section{Upper extremity impact}

Upper extremity impacts comprised two broad categories: elbow to head and hand/wrist/forearm to head. In the elbow to head scenario, typically both players are jumping to head a ball. One of them extends their elbows outwards to establish and protect their space and typically contacts the side of their opponent's head. In the hand/wrist/forearm to head scenario, one player forcefully extends their arm into the path of their opponent's head, typically contacting them across the side or front of the head.

We could establish impact speed estimates from video clip analysis in some cases of elbow to head contact, where a camera view was available perpendicular to the event, but not

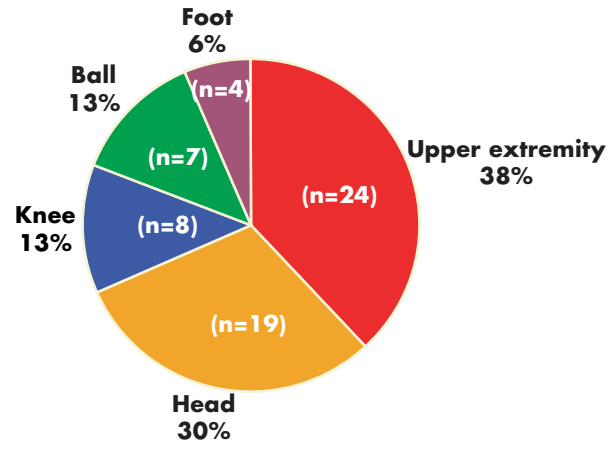

Figure 1 Relative frequency of head impact from F-MARC video of 62 cases. for hand/wrist/forearm to head, where motions typically occur in a horizontal plane and overhead game video was missing. Speed estimates were based on techniques developed from analysis of American football player impacts whereby video is digitised, and then distance in pixels plotted in a frame by frame manner as the elbow approached the head. ${ }^{21-23}$ Using the diameter of the game ball as a scaling reference, these distance measurements can be calibrated from pixels to metres. Then, using the known PAL framing rate of 25 fps (European standard), a time step is obtained to convert the distances to speeds.

\section{Upper extremity laboratory re-enactment}

Laboratory re-enactment of elbow to head and hand/wrist/ forearm to head cases was accomplished by volunteer subjects striking an instrumented crash test manikin. The manikin was a 50th percentile adult male Hybrid III dummy (Denton ATD Inc., Milan, OH). We used the pedestrian model rather than the more common seated version due to its increased hip mobility and ability to be positioned in an upright stance.

The Hybrid III dummy neck is made of rubber discs and aluminium spacers. There is a central steel cable to tune the neck's stiffness and maintain its integrity in automotive crash tests. This, unfortunately, leads to a neck that is arguably overly stiff in low-level impacts. It was desirable to reduce the stiffness of the neck to offer less resistance to the volunteers, as well as to reduce the likelihood of hurting them. For this reason, we removed the neck cable from the dummy neck for all volunteer testing. Additional padding was fitted to the dummy around the shoulder joint and the neck to cover any exposed metal parts.

A mobile structural frame was contrived to support the dummy for the elbow to head and hand/wrist/forearm to head trials. Figure 2 shows the dummy, suspended by a rigid bar affixed its lower thoracic spine, similar to a marionette. Its height was adjusted so that the dummy's feet were approximately $30 \mathrm{~cm}$ above the floor, forcing the subjects to jump to deliver a realistic blow.

The manikin head was instrumented with nine linear accelerometers in the so called 3-2-2-2 configuration which enabled the measurement of both linear and angular head

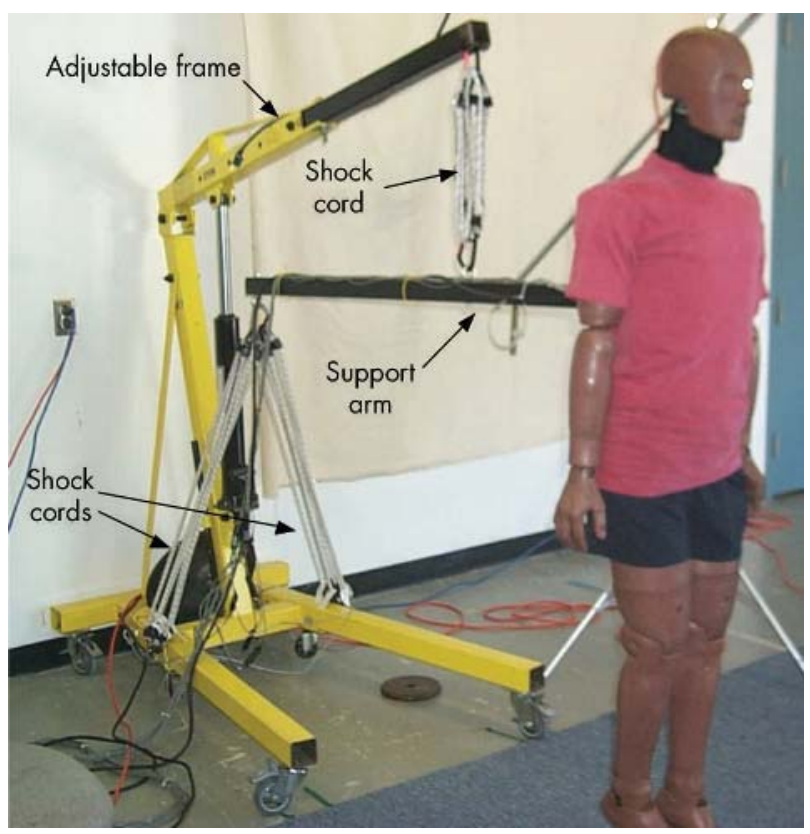

Figure 2 Hybrid III test manikin and support fixture. 


\begin{tabular}{|c|c|c|c|c|}
\hline Subject & Age & $\begin{array}{l}\text { Height } \\
\text { (cm) }\end{array}$ & $\begin{array}{l}\text { Weight } \\
\text { (kg) }\end{array}$ & $\begin{array}{l}\text { Years } \\
\text { playing }\end{array}$ \\
\hline 1 & 25 & 173 & 77.6 & 20 \\
\hline 2 & 25 & 160 & 72.1 & 14 \\
\hline 3 & 20 & 170 & 68.0 & 6 \\
\hline 4 & 19 & 175 & 80.7 & 14 \\
\hline 5 & 30 & 170 & 77.1 & 12 \\
\hline Mean & 23.8 & 169.6 & 75.1 & 13.2 \\
\hline SD & 5.15 & 9.19 & 15.37 & 10.45 \\
\hline $95 \% \mathrm{Cl} \pm$ & 4.51 & 8.06 & 13.47 & 9.16 \\
\hline
\end{tabular}

accelerations. ${ }^{24}$ The upper neck was instrumented with a six axis load cell, enabling the measurement of upper neck forces and bending torques. We collected all impact test data following the SAE J211-1 (Society of Automotive Engineers) protocol. ${ }^{25}$ Conventional video as well as high speed video (Motionscope 1000, Redlake Imaging, USA) was recorded to confirm impact speeds and impact kinematics.

\section{Volunteer test subjects}

The criteria for test subject selection included: healthy and experienced football player, age 18-30 years, nominally 50th percentile in weight and stature, and no history of significant injury to the upper extremities and shoulders. The five volunteers who participated in the study had average height $169.6 \mathrm{~cm}(95 \%$ CI 164.5 to $174.7 \mathrm{~cm})$ and mass $75.1 \mathrm{~kg}(95 \%$ CI 70.7 to $79.5 \mathrm{~kg}$ ) and were similar in size and weight to the 50 th percentile manikin $(175 \mathrm{~cm}, 78 \mathrm{~kg})$. The physical anthropometrical data of the players in the game video were not available. All subjects underwent an interview and orthopaedic medical screening by Dr R Gittens, who was also present during all laboratory testing.

All activity involving human subjects was reviewed and approved by the Ottawa Hospital Research Ethics Board. The subjects' physical details are given in table 1.

\section{Elbow to head laboratory tests}

The test subjects were shown video clips of elbow to head incidents so that they could re-enact the impact with the test manikin. The test consisted of the subject taking two or three strides and then jumping into the dummy. A key instruction that we gave to the subjects was to jump with their elbows up and not to extend their elbow into the dummy's head. A football was suspended in the air above and in front of the dummy to further simulate game conditions and to provide a point of focus for realistic simulation.

Given the repetitive nature of the testing, and the relative hardness of the Hybrid III head, it was necessary to provide the subjects with protective padding. A key consideration in the selection of the padding was the need not to be overprotective. If the subject was shielded completely from the impact, they would hit the dummy much harder than the field situation which was being replicated. It was important to select padding which, while protecting from injury, would still provide feedback to the subject about the magnitude of the impact. Soft padding was therefore desirable, as opposed to hard capped padding. Lacrosse arm guards (Avalanche, Brine Inc., USA) were selected for the elbow to head trials. Every subject performed 10 repeats to account for speed and aim variability. A film-strip sequence of an elbow to head laboratory re-enactment is shown in fig 3.

There was a tendency for each successive hit to be slightly more energetic than the previous, owing to both personal ambition and spirited feedback from the other participants in audience. For this reason, there is reasonable confidence that

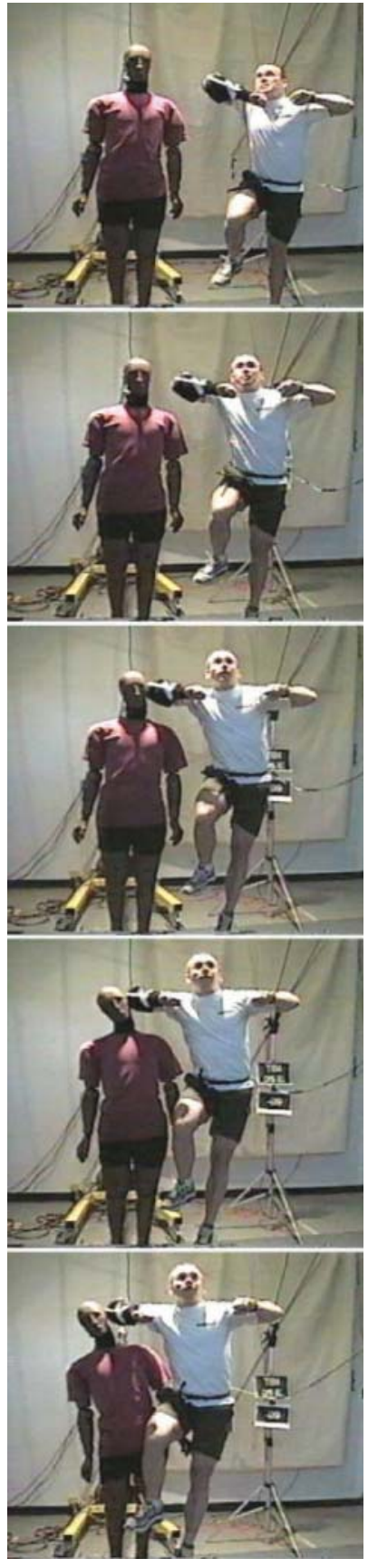

Figure 3 Elbow to head laboratory re-enactment. Images are in sequence from top to bottom.

each subjects struck the dummy as hard as possible, at least to their personal limit of discomfort.

\section{Hand/wrist/forearm to head laboratory tests}

Using the same test set-up as that used for the elbow to head simulations, hand/wrist/forearm to head impacts were recreated to simulate on-field incidents. The test subjects performed 10 trials each. They were instructed to take a step and jump, and aggressively extend their arm in a lateral direction, making contact with the side of the dummy's head with full force, as shown in the overhead film-strip sequence in fig 4. A lightweight and relatively soft forearm/hand guard intended for martial arts training (Macho Products Inc. "Cloth Forearm Hand Guard", USA) was used to protect the subjects, and still provide a reasonable degree of feedback. 


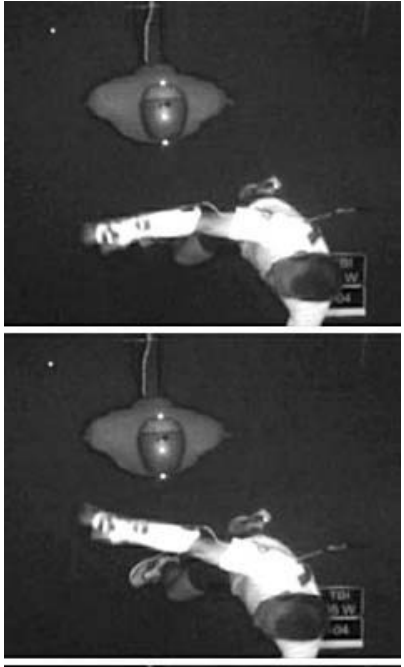

Figure 4 Hand/wrist/forearm to head laboratory re-enactment, overhead view. Images are in sequence from top to bottom.
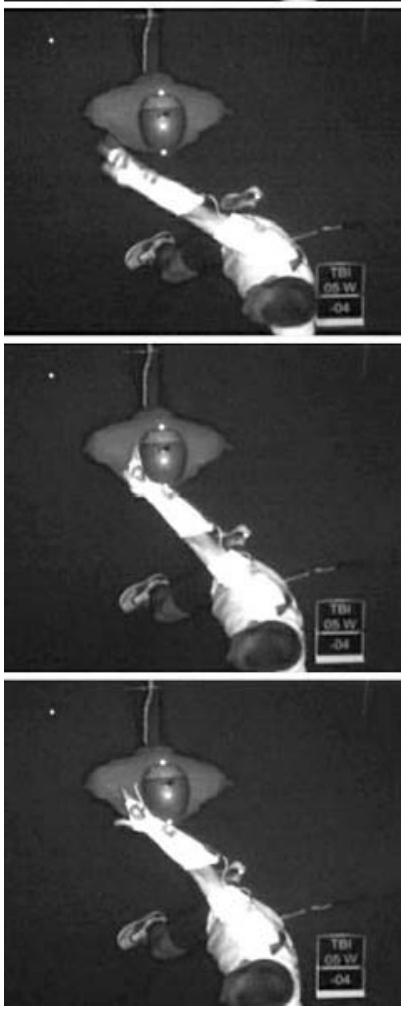

\section{Head to head impact}

Based on the game video, head to head impact comprised two general scenarios. The first was impact by the off-centre forehead to the rear of another's head and the second impact by the front boss (that is, outer corner of the forehead at the hairline) to the side of another's head.

It was not feasible for volunteer subjects to re-enact this in the laboratory due to concerns about injury. Instead, we used two crash test dummy heads to represent both the striking and struck players, as shown in fig 5. The dummy representing the struck player was instrumented to measure linear and angular accelerations, as well as upper neck forces and torques.

An overall view of the laboratory set-up is shown in fig 6 . We mounted the falling head and neck on a carriage that ran up and down a square vertical column. The stationary head and neck were mounted to the torso of a Hybrid III crash test manikin, which was in turn supported by a yoke assembly

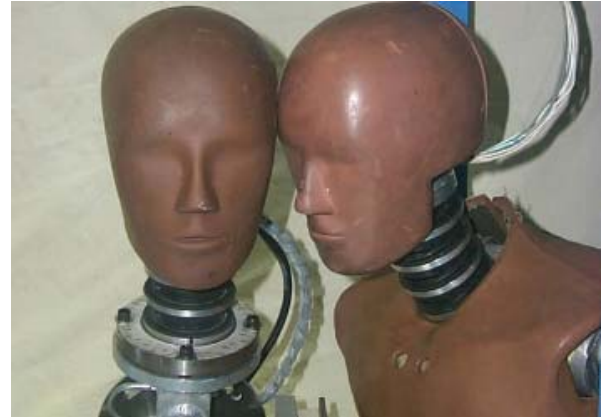

Figure 5 Laboratory re-enactment of forehead to side impact. This image is turned $90^{\circ}$ to illustrate the similarity to a game collision, but testing was done with the left head falling onto the right head.

suspended from a test frame with elastic shock cords. In this fashion, the struck dummy may rebound on impact for a more realistic contact event. The carriage assembly was raised to a height to yield a calculated impact speed, and released. The same data acquisition system and parameters were used as described earlier.

In a game impact, usually both players' heads have some velocity prior to impact, and the combination of speed from each player towards the other is called the closing speed. In the laboratory all of this speed is given to one of the heads while the other head is stationary. Because both heads are of similar mass, conservation of momentum is satisfied.

\section{Injury indices}

Our data presentation shall focus on injury indices related to head acceleration and neck forces and moments. The objective of our study was to determine the risk of injury to a player who may experience the same impact on the playing field. The Hybrid III is an automotive crash test dummy and literature on dummy test data to injury potential relates mostly to automotive research where the aim is to reduce the risk of severe injuries. An exception here is the work by Newman et $a l^{212627}$ in which videos of National Football League (NFL, American football) players, both uninjured and those who sustained concussions, were analysed, the collisions re-enacted with Hybrid III dummies, and the measured head response related to the risk of concussion. Logist plots relating the risk of concussion with various parameters including peak linear and angular head accelerations and the maximum HIP (HIPmax) ${ }^{26}$ are provided in Appendix l. HIP is

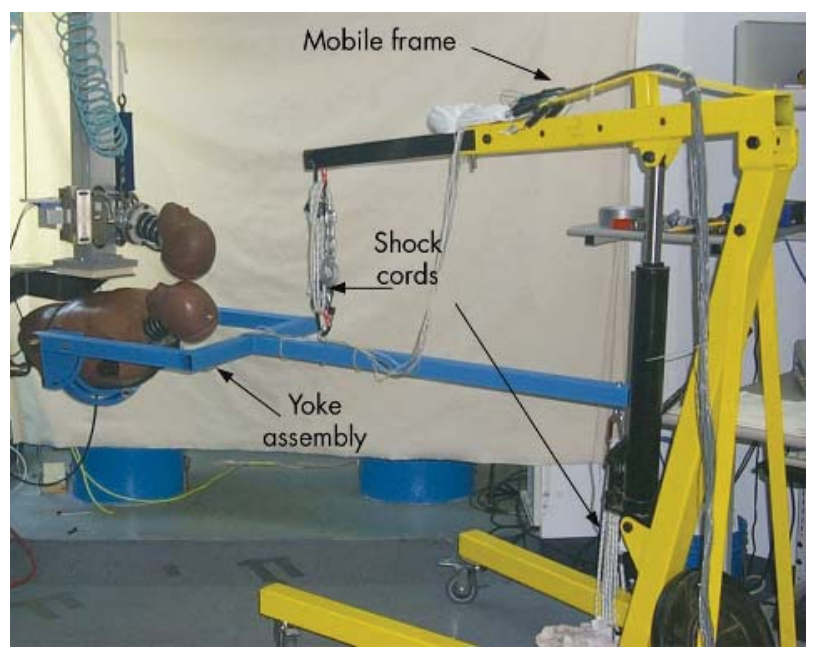

Figure 6 Head to head laboratory test set-up. 


\begin{tabular}{|c|c|c|c|c|c|c|}
\hline \multirow[b]{2}{*}{ Region } & \multirow[b]{2}{*}{ Measured value } & \multirow[b]{2}{*}{ Units } & \multicolumn{3}{|c|}{ Injury tolerance by risk } & \multirow[b]{2}{*}{ Injury } \\
\hline & & & $5 \%$ & $50 \%$ & $95 \%$ & \\
\hline \multirow[t]{3}{*}{ Head $^{*}$} & $\begin{array}{l}\text { Head impact power } \\
\text { (HIPmax) }\end{array}$ & kW & 4.50 & 12.8 & 21.3 & Concussion \\
\hline & $\begin{array}{l}\text { Peak resultant linear } \\
\text { acceleration }\end{array}$ & g & 40 & 78 & 115 & Concussion \\
\hline & $\begin{array}{l}\text { Peak resultant } \\
\text { rotational acceleration } \\
\text { (a) }\end{array}$ & $\mathrm{rad} / \mathrm{s}^{2}$ & 3350 & 6350 & 9250 & Concussion \\
\hline \multirow[t]{6}{*}{ Neckt } & +Fz (tension) & $\mathrm{N}$ & +1097 & - & - & Als $3+$ \\
\hline & $-\mathrm{Fz}$ (compression) & $\mathrm{N}$ & -1100 & - & - & AIS $3+$ \\
\hline & Fxy (resultant shear) & $\mathrm{N}$ & 1100 & - & - & AIS $3+$ \\
\hline & +My (flexion) & $\mathrm{Nm}$ & 190 & - & - & AIS $3+$ \\
\hline & -My (extension) & $\mathrm{Nm}$ & -77 & - & - & AIS $3+$ \\
\hline & $\pm M x$ (lateral flexion) & $\mathrm{Nm}$ & 143 & - & - & AIS $3+$ \\
\hline $\begin{array}{l}\text { *Based o } \\
\text { †Based } \\
\text { AlS, abb }\end{array}$ & $\begin{array}{l}\text { Newman ef al. } \\
\text { Mertz.". } \\
\text { viated injury scale. }\end{array}$ & & & & & \\
\hline
\end{tabular}

the rate of change of energy imparted to the head. Mathematically it comprises the product of head mass, acceleration, and velocity plus the product of the head's moment of inertia, angular acceleration, and angular velocity. The maximum power has been reported to be the best overall prediction function related to concussion, and it is described in detail by Shewchenko et $a l^{28}$ in this supplement. Pellman et $a l^{22}$ did not consider maximum power in their analysis of NFL data and found linear acceleration correlated best with concussion. Although the logistic functions cover risk factors between $0 \%$ and $100 \%$, we focused particularly on the $5 \%$, $50 \%$, and $95 \%$ risk levels. The $5 \%$ risk is commonly used with the Hybrid III dummy to represent an "unlikely injury". ${ }^{29}$ Conversely, the $95 \%$ risk may be interpreted as almost certain

\begin{tabular}{|c|c|c|}
\hline Case & $\begin{array}{l}\text { Speed } \\
(\mathrm{m} / \mathrm{s})\end{array}$ & Injury reported \\
\hline 1 & 1.3 & \multirow{8}{*}{$\begin{array}{l}\text { Head wound } \\
\text { Scalp laceration } \\
\text { Lower lip } \\
\text { Nose fracture, skull trauma } \\
\text { Head contusion-severity } 2 \text { days } \\
\text { Facial laceration-severity } \\
3 \text { days }\end{array}$} \\
\hline 2 & 4.1 & \\
\hline 3 & 1.0 & \\
\hline 4 & 2.8 & \\
\hline 5 & 5.3 & \\
\hline 6 & 3.7 & \\
\hline $\begin{array}{l}\text { Mean } \\
\text { SD }\end{array}$ & $\begin{array}{l}3.03 \\
1.67\end{array}$ & \\
\hline $95 \% \mathrm{Cl} \pm$ & 1.33 & \\
\hline
\end{tabular}

injury. This range may therefore be interpreted as almost no risk, even chances, and almost certain risk of concussion.

For neck injury, we compared forces and bending torques with the Injury Assessment Reference Values (IARVs) described by Mertz. ${ }^{30}$ Each IARV was chosen such that if the value was not exceeded, a corresponding injury was unlikely to occur, where "unlikely" is defined as a less than $5 \%$ risk of significant injury (that is, abbreviated injury scale (AIS) $3+$ ). This level of injury is arguably higher than the minor sprains and strains typically associated with football, but there is no lesser severity index available. These data are based on a series of experiments using anaesthetised porcine test subjects in the path of deploying airbags. ${ }^{29}$ Autopsied injuries of the test subjects were related to impact forces and torques, and then the data were scaled to that of various sized humans. Of interest here is the data related to the Hybrid III test dummy neck output. Data are provided for flexionextension and lateral bending, and tension-compression and shear forces. For some data, the IARVs are related to time duration, the rationale being that injury is related to load induced displacements, and that one can withstand higher forces for shorter impact durations and vice versa. This is important in relation to the relatively long duration contact with an airbag in a car crash, but may be less critical in relation to the shorter duration contact typical of football head impact. Also, some of the IARVs describe higher tolerance levels for tensed compared with relaxed subjects. The IARVs for upper neck injury are provided in Appendix 2. For purposes of the current study, we chose the lowest IARVs regardless of impact duration, and the unsuspecting players were considered non-tensed. Table 2 gives a summary of the injury thresholds used in comparison with test scores.

\section{RESULTS}

Of the 18 video cases of elbow to head contact, only six were suitable for measuring impact speeds. These are given in table 3. The data show a range of $1.0-5.3 \mathrm{~m} / \mathrm{s}$ with a mean of $3.03 \mathrm{~m} / \mathrm{s}(95 \%$ CI 1.70 to $4.37 \mathrm{~m} / \mathrm{s})$. Note that these data are not intended to relate injury outcome with impact speed, only to guide laboratory re-enactments. Also note that there were no concussions among these particular cases.

A summary of the elbow to head and hand/wrist/forearm to head tests is provided in table 4 . The volunteers' impact speeds for the two configurations were resolved by way of high speed video positioned above the manikin and looking directly downwards. The kinematics of impact were predominantly in the horizontal plane, therefore analysis of motion in this plane alone was sufficient for velocity measurement. Retro-reflective markers on the test subject's arms and wrists, as well as the manikin's head, allowed for calculation of the closing impact speed. For elbow to head

Table 4 Summary of upper extremity volunteer test data ( 5 subjects $\times 10$ repeats $=50$ tests $)$

\begin{tabular}{|c|c|c|c|c|c|c|c|c|c|c|c|}
\hline & & \multirow[b]{2}{*}{$\begin{array}{l}\text { Impact speed } \\
(\mathrm{m} / \mathrm{s})\end{array}$} & \multicolumn{3}{|l|}{ Head } & \multicolumn{6}{|l|}{ Neck } \\
\hline & & & $\begin{array}{l}\text { Linear } \\
\text { accel. } \\
\text { (g) }\end{array}$ & $\begin{array}{l}\text { Angular } \\
\text { accel. } \\
\left(\mathrm{rad} / \mathrm{s}^{2}\right)\end{array}$ & $\begin{array}{l}\text { HIPmax } \\
(\mathrm{kW})\end{array}$ & $\begin{array}{l}\text { Tension } \\
\text { (N) }\end{array}$ & $\begin{array}{l}\text { Compression } \\
\text { (N) }\end{array}$ & $\begin{array}{l}\text { Shear } \\
\text { (N) }\end{array}$ & $\begin{array}{l}\text { Flexion } \\
\text { (Nm) }\end{array}$ & $\begin{array}{l}\text { Extension } \\
(\mathrm{Nm})\end{array}$ & $\begin{array}{l}\text { Lateral } \\
\text { flexion } \\
(\mathrm{Nm})\end{array}$ \\
\hline \multirow{5}{*}{$\begin{array}{l}\text { Elbow } \\
(n=50)\end{array}$} & Minimum & 1.7 & 4.0 & 357 & 0.1 & 20 & -169 & 116 & 0.7 & -15.8 & 5.1 \\
\hline & Maximum & 4.6 & 48.2 & 3812 & 3.4 & 496 & -6 & 625 & 14.9 & -0.1 & 50.1 \\
\hline & Mean & 3.02 & 21.3 & 1611 & 1.1 & 174 & -46 & 260 & 3.3 & -3.3 & 15.7 \\
\hline & SD & 0.58 & 10.14 & 891.3 & 0.76 & 126.1 & 37.1 & 92.5 & 2.26 & 2.53 & 9.80 \\
\hline & $95 \% \mathrm{Cl} \pm$ & 0.16 & 2.81 & 247.1 & 0.21 & 35.0 & 10.3 & 25.6 & 0.63 & 0.70 & 2.72 \\
\hline \multirow{5}{*}{$\begin{array}{l}\text { Hand/ } \\
\text { wrist/ } \\
\text { forearm } \\
(n=50)\end{array}$} & Minimum & 5.2 & 7.4 & 481 & 0.1 & 37 & -666 & 92 & 3.0 & -9.7 & 0.8 \\
\hline & Maximum & 9.3 & 44.4 & 3273 & 1.9 & 225 & -27 & 507 & 37.8 & -1.8 & 28.1 \\
\hline & Mean & 7.67 & 20.4 & 1445 & 0.6 & 86 & -138 & 282 & 20.7 & -5.4 & 11.9 \\
\hline & SD & 0.91 & 7.72 & 636.6 & 0.38 & 47.4 & 110.1 & 89.4 & 10.74 & 1.75 & 6.72 \\
\hline & $95 \% \mathrm{Cl} \pm$ & 0.25 & 2.14 & 176.5 & 0.11 & 13.1 & 30.5 & 24.8 & 2.98 & 0.49 & 1.86 \\
\hline
\end{tabular}


Table 5 Exposure rates for concussion and significant neck injury from elbow-head (E-H) and hand/wrist/forearm-head (H/W/F) impacts

\begin{tabular}{|c|c|c|c|c|c|c|c|c|c|c|c|c|c|c|c|}
\hline \multirow[b]{3}{*}{ Risk level (\%) } & \multicolumn{9}{|c|}{ Concussion } & \multicolumn{6}{|c|}{ Significant neck injury (AIS 3+) } \\
\hline & \multicolumn{3}{|c|}{$\begin{array}{l}\text { Linear accel. } \\
\text { (g) }\end{array}$} & \multicolumn{3}{|c|}{$\begin{array}{l}\text { Angular accel. } \\
\left(\mathrm{rad} / \mathrm{s}^{2}\right)\end{array}$} & \multicolumn{3}{|l|}{$\begin{array}{l}\text { HIP } \\
(\mathrm{kW})\end{array}$} & \multirow{2}{*}{$\begin{array}{l}\begin{array}{l}\text { Tension } \\
\text { (N) }\end{array} \\
5\end{array}$} & \multirow{2}{*}{$\begin{array}{l}\begin{array}{l}\text { Compression } \\
\text { (N) }\end{array} \\
5\end{array}$} & \multirow{2}{*}{$\begin{array}{l}\text { Shear } \\
\text { (N) } \\
5\end{array}$} & \multirow{2}{*}{$\begin{array}{c}\begin{array}{l}\text { Flexion } \\
\text { (Nm) }\end{array} \\
5\end{array}$} & \multirow{2}{*}{$\begin{array}{l}\text { Extension } \\
\text { (Nm) }\end{array}$} & \multirow{2}{*}{$\begin{array}{c}\text { Lateral } \\
\text { flexion } \\
(\mathrm{Nm})\end{array}$} \\
\hline & 5 & 50 & 95 & 5 & 50 & 95 & 5 & 50 & 95 & & & & & & \\
\hline Reference value & 40 & 78 & 115 & 3350 & 6350 & 9250 & 4.5 & 12.8 & 21.3 & 1097 & -1100 & 1100 & 190 & -77 & 143 \\
\hline E-H exposure rate (\%) & 3.29 & 0 & 0 & 2.56 & 0 & 0 & 0 & 0 & 0 & 0 & 0 & 0 & 0 & 0 & 0 \\
\hline $\begin{array}{l}\mathrm{H} / \mathrm{W} / \mathrm{F} \text { exposure rate } \\
\text { (\%) }\end{array}$ & 0.55 & 0 & 0 & 0.14 & 0 & 0 & 0 & 0 & 0 & 0 & 0 & 0 & 0 & 0 & 0 \\
\hline
\end{tabular}

tests, the impact speed ranged from $1.7 \mathrm{~m} / \mathrm{s}$ to $4.6 \mathrm{~m} / \mathrm{s}$ with an overall mean of $3.02 \mathrm{~m} / \mathrm{s}$ (95\% CI 2.86 to $3.18 \mathrm{~m} / \mathrm{s}$ ) which was similar to the video $(\mathrm{p}=0.98)$. Hand/wrist/forearm to head impact speeds ranged from $5.2 \mathrm{~m} / \mathrm{s}$ to $9.3 \mathrm{~m} / \mathrm{s}$ with an overall mean of $7.67 \mathrm{~m} / \mathrm{s}$ (95\% CI 7.42 to $7.93 \mathrm{~m} / \mathrm{s})$. Game video analysis of this manoeuvre was not possible for comparison.

Of the 19 head to head video clips, only three were appropriate for a calculating speed estimates. These are shown in table 5 and have a range of $1.3-2.5 \mathrm{~m} / \mathrm{s}$. The literature lacks information of typical head-head collision speed in football, and this sample was too small for statistical interpretation (table 6). To err on the side of caution, the upper observed speed was rounded to $3.0 \mathrm{~m} / \mathrm{s}$ for the laboratory tests, and $1.5 \mathrm{~m} / \mathrm{s}$ was

\begin{tabular}{|lll|}
\hline $\begin{array}{l}\text { Table } 6 \\
\text { impacts }\end{array}$ & Estimated speed for head-head game \\
\hline Case clip & Speed $(\mathrm{m} / \mathrm{s})$ & Injury reported \\
\hline 7 & 1.3 & Head contusion-severity 1 \\
8 & 1.8 & Head contusion-severity 4 \\
9 & 2.5 & Head contusion-severity 2 \\
\hline
\end{tabular}

chosen as a halfway comparison that also represented the lower end of the video head collisions. The nature of using a manikin head in guided freefall is well known to be very repeatable. To confirm this, three repeats were done for each configuration and speed. Test results are shown in table 7. Impact speed was measured by a light-beam trap gate immediately before impact. The small variations in the three repeat tests confirmed good repeatability, and injury risks are presented relative to the means of the repeats.

For the $1.5 \mathrm{~m} / \mathrm{s}$ tests in both configurations, all scores remained below 5\% risk for concussion and AIS 3+ neck injury. For the $3 \mathrm{~m} / \mathrm{s}$ tests, neck injury risk continued to remain below $5 \%$ for AIS 3+, but risk of concussion for front boss to side and forehead to rear was $67 \%$ and $53 \%$, respectively, based on acceleration, and $11 \%$ and $7 \%$, respectively, based on HIPmax.

\section{DISCUSSION}

Five test subjects performed 10 repeats of two upper extremity test scenarios for a total of 100 upper extremity impact data sets. This volume of test data was needed to account for variation both among and between the volunteer test subjects as well as to provide a better opportunity to achieve a realistic "worst

Table 7 Summary of head to head peak impact test data. Notable injury risk is highlighted in bold

\begin{tabular}{|c|c|c|c|c|c|c|c|c|c|c|}
\hline & & \multicolumn{3}{|l|}{ Head } & \multicolumn{6}{|l|}{ Neck } \\
\hline & & $\begin{array}{l}\text { Linear } \\
\text { accel. } \\
\text { (g) }\end{array}$ & $\begin{array}{l}\text { Angular } \\
\text { accel. } \\
\left(\mathrm{rad} / \mathrm{s}^{2}\right)\end{array}$ & $\begin{array}{l}\text { HIPmax } \\
\text { (kW) }\end{array}$ & $\begin{array}{l}\text { Tension } \\
\text { (N) }\end{array}$ & $\begin{array}{l}\text { Compression } \\
\text { (N) }\end{array}$ & $\begin{array}{l}\text { Shear } \\
\text { (N) }\end{array}$ & $\begin{array}{l}\text { Flexion } \\
(\mathrm{Nm})\end{array}$ & $\begin{array}{l}\text { Extension } \\
(\mathrm{Nm})\end{array}$ & $\begin{array}{l}\text { Lateral } \\
\text { flexion }(\mathrm{Nm})\end{array}$ \\
\hline \multicolumn{11}{|l|}{ Front boss to side } \\
\hline \multirow[t]{6}{*}{$1.5 \mathrm{~m} / \mathrm{s}$} & & 34.2 & 2743 & 1.6 & 58 & -19 & 146 & 0.3 & -0.4 & 10.6 \\
\hline & & 35.7 & 2789 & 1.6 & 61 & -31 & 163 & 0.4 & -0.2 & 11.0 \\
\hline & & 35.5 & 2777 & 1.6 & 56 & -19 & 166 & 0.4 & -0.2 & 10.4 \\
\hline & Mean & 35.1 & 2770 & 1.6 & 58 & -23 & 158 & 0.4 & -0.3 & 10.7 \\
\hline & & 0.8 & 24 & 0.0 & 2 & 7 & 11 & 0.1 & 0.1 & 0.3 \\
\hline & Risk (\%) & $<5$ & $<5$ & $<5$ & $<5$ & $<5$ & $<5$ & $<5$ & $<5$ & $<5$ \\
\hline \multirow[t]{6}{*}{$3.0 \mathrm{~m} / \mathrm{s}$} & & 86.3 & 7052 & 6.9 & 120 & -54 & 469 & 0.7 & -0.7 & 15.5 \\
\hline & & 87.0 & 7048 & 7.0 & 142 & -20 & 480 & 0.4 & -0.8 & 15.0 \\
\hline & & 86.6 & 6998 & 6.9 & 129 & -37 & 475 & 0.9 & -0.6 & 14.9 \\
\hline & Mean & 86.7 & 7033 & 6.9 & 130 & -37 & 475 & 0.7 & -0.7 & 15.1 \\
\hline & & 0.3 & 30 & 0.0 & 11 & 17 & 6 & 0.2 & 0.1 & 0.4 \\
\hline & Risk (\%) & 67.0 & 67 & 11.0 & $<5$ & $<5$ & $<5$ & $<5$ & $<5$ & $<5$ \\
\hline \multicolumn{11}{|l|}{ Forehead to rear } \\
\hline \multirow{6}{*}{$1.5 \mathrm{~m} / \mathrm{s}$} & & 34.8 & 1492 & 1.7 & 105 & -153 & 200 & 0.0 & -9.9 & 0.7 \\
\hline & & 35.6 & 1519 & 1.8 & 99 & -180 & 198 & 0.1 & -10.2 & 0.9 \\
\hline & & 35.6 & 1529 & 1.8 & 94 & -164 & 202 & 0.1 & -10.1 & 0.8 \\
\hline & Mean & 35.3 & 1513 & 1.7 & 99 & -166 & 200 & 0.1 & -10.1 & 0.8 \\
\hline & SD & 0.5 & 19 & 0.0 & 5 & 14 & 2 & 0.0 & 0.1 & 0.1 \\
\hline & Risk (\%) & $<5$ & $<5$ & $<5$ & $<5$ & $<5$ & $<5$ & $<5$ & $<5$ & $<5$ \\
\hline \multirow{6}{*}{$3.0 \mathrm{~m} / \mathrm{s}$} & & 79.0 & 3115 & 5.8 & 165 & -364 & 450 & 0.2 & -14.1 & 1.3 \\
\hline & & 79.2 & 3106 & 5.8 & 178 & -363 & 462 & 0.3 & -14.1 & 1.2 \\
\hline & & 79.0 & 3078 & 5.7 & 174 & -383 & 449 & 0.4 & -13.8 & 1.6 \\
\hline & Mean & 79.0 & 3100 & 5.8 & 172 & -370 & 454 & 0.3 & -14.0 & 1.4 \\
\hline & SD & 0.1 & 19 & 0.0 & 7 & 11 & 8 & 0.1 & 0.2 & 0.2 \\
\hline & Risk (\%) & 53.0 & $<5$ & 7.0 & $<5$ & $<5$ & $<5$ & $<5$ & $<5$ & $<5$ \\
\hline
\end{tabular}




\section{What is already known on this topic}

Clinical evidence suggests that a large proportion of nonheader head impacts occur during aerial tackles and header competitions, and are generally delivered by the upper extremity or head of the opponent. However, the potential for head and neck injury from this activity, whether it be incidental or intentional is not well understood.

case" scenario. The data in table 4 include the lowest and highest single scores for all parameters measured, as well as the means, standard deviations, and 95\% confidence intervals. Mean head accelerations and HIPmax remained below even a $5 \%$ risk level for concussion, although there were a few acceleration data points higher than this risk. The immediate observation after comparing the upper extremity test data in table 4 with the injury reference values in table 2 is that overall test scores are very low, indicating low risks of concussion and significant neck injury. No neck data were even close to the IARVs although the overall maxima of neck shear forces generated in the elbow and hand/wrist/forearm tests were roughly half the $1100 \mathrm{~N}$ required for AIS3+ $(625 \mathrm{~N}$ and $507 \mathrm{~N}$, respectively). This is perhaps to be expected for neck injury IARVs, which by definition describes a serious injury not often seen in football, but it is surprising that such low risk of concussion is measured in what appeared during testing to be very aggressive head impacts.

To examine those few individual tests where 5\% risk of concussion was exceeded, table 5 presents the upper extremity test data in terms of exposure rate. A normal distribution of all test scores is assumed, and the probability is calculated for the percentage of cases for which a particular injury parameter would be exceeded by $z=(c-\mu) / s$ from a normal distribution function table where $c$ is the critical injury value, $\mu$ is the mean, and $s$ is the standard deviation. The data suggest that a linear or angular acceleration of a sufficient level to achieve a $5 \%$ risk of concussion would occur roughly three times in 100 from elbow contact, and less than once in 100 from hand/wrist/forearm contact.

The reasons for such low injury risk may lie in a number of places. Firstly, the elbow and wrist padding used to protect the test subjects may have attenuated too much of the impact. Obviously players do not wear upper extremity padding on the field, but at the same time, a Hybrid III head is much stiffer than a human's and the absence of padding in these tests would have been prohibitive. All padding was "soft" in that there was no hard outer cap, as is seen for instance in hockey gear. This was to ensure that there was at least some degree of feedback to the person, and indeed volunteer feedback indicated that while impacts were not painful, there was definitely the sensation of impact. Secondly, another reason might be that the level of aggression during match play is higher than that achieved in the laboratory. Our volunteers were instructed to be aggressive in their impacts, and indeed there was some good natured rivalry between the subjects to achieve high scores. But whether these staged events compare with the adrenaline-charged aggression of match play remains unclear. A final, and perhaps the most plausible, reason for the low concussion risk scores could simply be that such impacts typically do not lead to concussions. It is not unreasonable to conclude this given that none of the players in the supplied video showed signs of having experienced a concussion. This is consistent with the medical records supplied for the re-enacted cases where only superficial injuries were diagnosed. This notion is also supported by recent work by Fuller et al, ${ }^{13}$ who showed that upper extremity impacts were found to be the most frequent cause of general head injuries but rarely of concussion.
What this study adds

This study provides biomechanical insight into the risks of head and neck injury associated with upper extremity and head to head collisions. The high potential for concussion in head to head impact may lead game regulators to consider countermeasures to reduce its occurrence.

On the other hand, there was high injury potential associated with head to head impact. At the $1.5 \mathrm{~m} / \mathrm{s}$ test speed, concussion and neck injury risks were negligible. However, at the $3.0 \mathrm{~m} / \mathrm{s}$ test speed for the front boss to side hit, peak linear and rotational accelerations both suggested a $67 \%$ risk of concussion. For the forehead to rear case at $3.0 \mathrm{~m} / \mathrm{s}$, peak linear acceleration suggested a 53\% risk of concussion. This is again supported by Fuller et al' $^{13}$ findings where head to head impact was found to result in the highest frequency of concussion. In no cases at either test speed did neck injury parameters even approach the $5 \%$ risk level. The reader is reminded that $3.0 \mathrm{~m} / \mathrm{s}$ appeared to be a reasonable depiction of head to head collision as seen in the supplied video. It also compares with Shewchenko et al' $^{28}$ findings where forward head speeds of $2.5-3.2 \mathrm{~m} / \mathrm{s}$ were observed in volunteer ball headings. This would be similar to a player competing for a jump ball and striking another's head rather than the ball. If future evidence suggests that higher speed collisions occur, the risks of injury risks would naturally be higher as well.

It is interesting to note the high risk values for mild traumatic brain injury were associated with peak accelerations, but not HIP scores. For the $67 \%$ concussion risk based on accelerations, there was only $11 \%$ risk from HIPmax. A likely explanation is the short impact duration of the head to head collisions. Short impact durations typically introduce small velocity changes, and since the prime component of power is the product of acceleration and velocity, small power values result. Since the data on which the NFL injury curves were created is based on helmeted head impact, which typically involves longer duration impacts than bare head hits, it is possible that the acceleration based indices are not entirely suitable for unpadded impact. In fact, none of the NFL based injury risk functions are validated against bare head impacts, but they remain the only available injury assessment criteria at these low severity levels.

It nevertheless does imply that head to head collisions in football, within the limits of the cases studied, potentially pose a more serious risk of brain injury than do upper extremity impacts. Although these collisions will occur as a consequence of player competitiveness, the intentional use of the head to strike another is clearly dangerous. In no case did it appear that typical upper extremity to head or head to head contact pose a neck injury threat.

\section{CONCLUSIONS}

Laboratory testing with human subjects striking an instrumented test manikin suggests that the risk of concussion and serious neck injury associated with upper extremity impact, based on the cases reviewed in the supplied video and the human subject testing, is very low. This is not to excuse other clinically relevant injuries such as contusion, lacerations, or even facial bone fractures, jaw dislocations, or neck strains. It merely suggests that infractions of this nature perhaps do not warrant stricter penalties on the sole basis of concussion or neck injury potential.

Head to head impact, whether intentional or not, poses a high risk of concussion. This is observed in the clinical literature and now confirmed by laboratory experiments. This information provides justification for more stringent efforts 
to reduce the occurrence of head to head impacts, whether that occurrence is incidental or intentional.

\section{ACKNOWLEDGEMENTS}

The authors would like to thank the FIFA Medical Assessment and Research Centre for its sponsorship of this research programme Further thanks is extended to the Gloucester Hornets and Kanata Soccer for contributing their time and spirited cooperation as volunteer test subjects. Also thanks to Professors Yiqiang Zhao and Chul Gyu Park, Carleton University Department of Mathematics (Ottawa, Canada) for their helpful suggestions on data presentation.

\section{Authors' affiliations}

C Withnall, N Shewchenko, R Gittens, Biokinetics and Associates Ltd. Ontario, Canada

J Dvorak, FIFA Medical Assessment and Research Centre, Zurich, Switzerland

Competing interests: none declared

\section{APPENDIX 1}
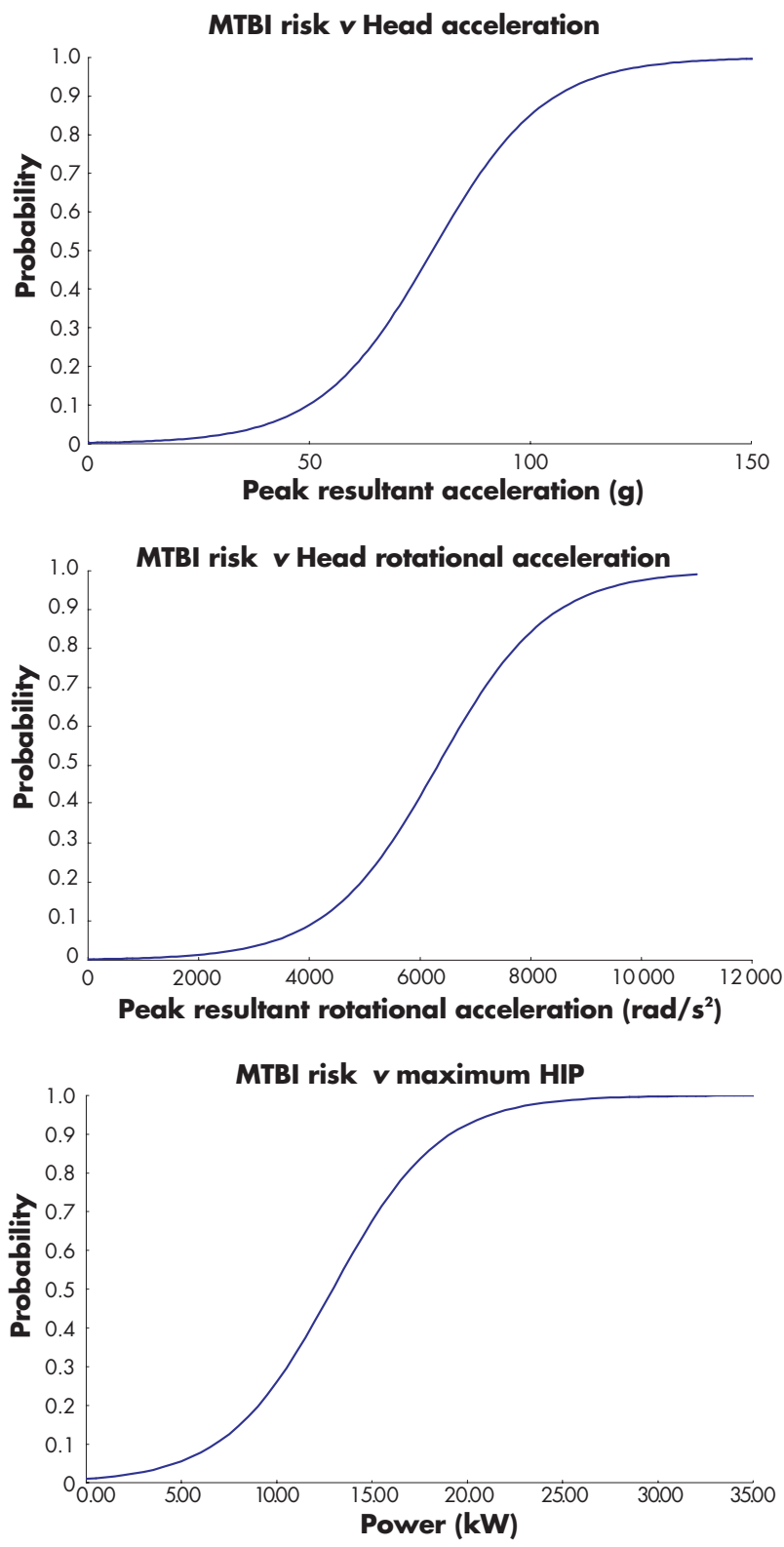

Figure 7 Head injury risk functions. From Newman et al. ${ }^{23} \mathrm{HIPI}$, Head Impact Power Index.

\section{APPENDIX 2}
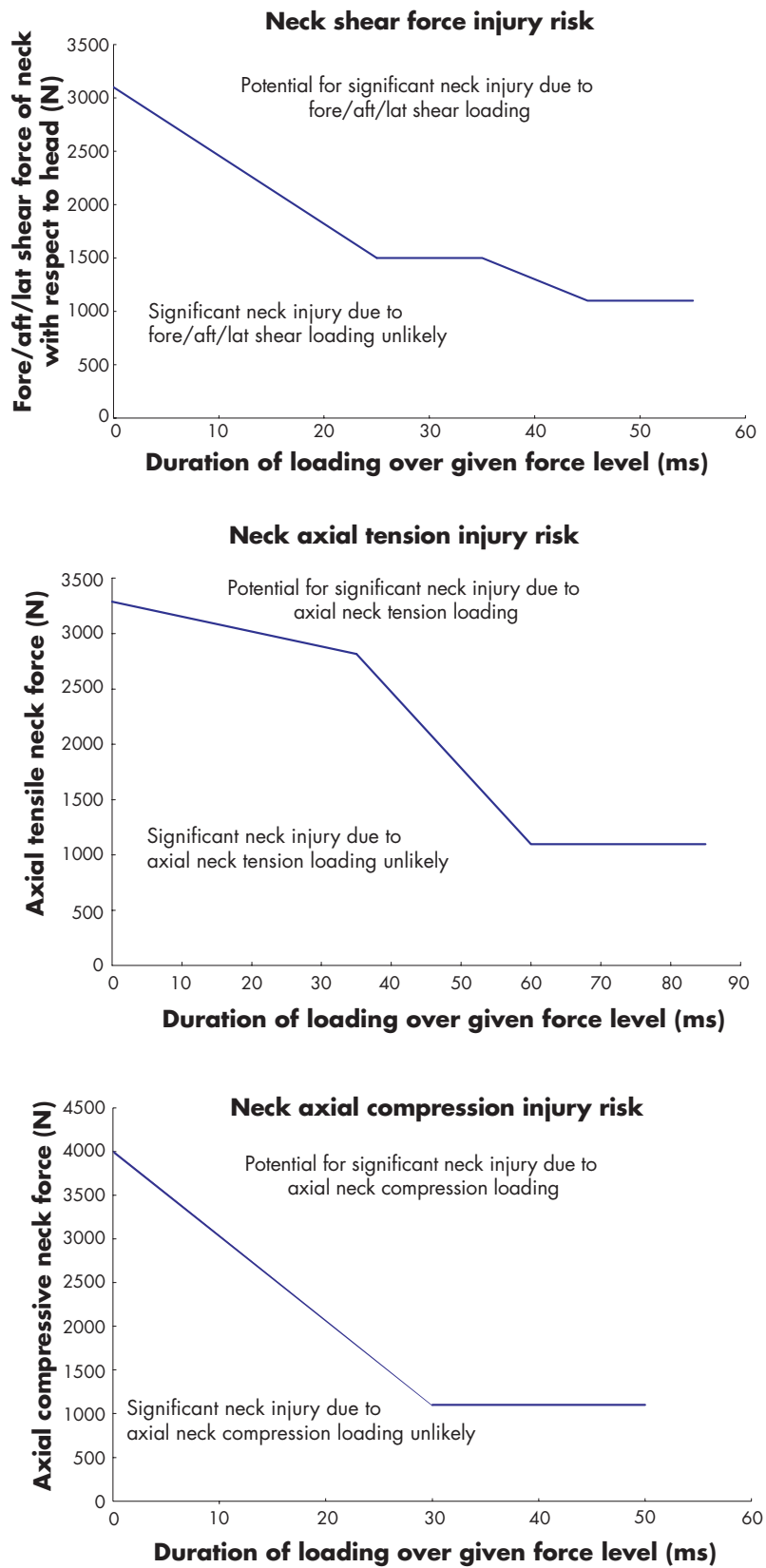

Figure 8 Neck injury assessment reference values (IARVs). From Mertz et al. ${ }^{29}$

\section{REFERENCES}

1 Tysvaer A. Head and neck injuries in soccer, impact of minor trauma. Sports Med 1992;14:200-13.

2 Kirkendall D, Jordan S, Garrett W. Heading and head injuries in soccer Sports Med 2001;31:369-86.

3 Matser J, Kessels A, Jordan B, et al. Chronic traumatic brain injury in professional soccer players. Am Acad Neurol 1998;51:791-6.

4 Matser J, Kessels A, Lezak M, et al. Neuropsychological impairment in amateur soccer players. JAMA 1999;282:971-73.

5 Matser E. Soccer related concussions. Br J Sports Med 2001;35:373-4

6 Tysvaer A, Lochen E. Soccer injuries to the brain. A neuropsychologic study of former soccer players. Am J Sports Med 1991;19:56-60.

7 Guskiewicz K, Marshall S, Broglio S, et al. No evidence of impaired neurocognitive performance in collegiate soccer players. Am J Sports Med 2002;30:157-62

8 Jordan S, Green G, Galanty H, et al. Acute and chronic brain injury in United States national team soccer players. Am J Sports Med 1996;24:205-10.

9 McCrory P. Brain injury and heading in soccer. BMJ 2003;327:351-2. 
10 Boden B Kirkendall D, Garrett W. Concussion incidence in elite college soccer players. Am J Sports Med 1998;26:238-41.

11 Barnes B, Cooper L, Kirkendall D, et al. Concussion history in elite male and female soccer players. Am J Sports Med 1998;26:433-8.

12 Andersen T, Arnason A, Engebretsen L, et al. Mechanisms of head injuries in elite football. Br J Sports Med 2004;38:690-6.

13 Fuller C, Junge A, Dvorak J. A six year prospective study of the incidence, aetiology and causes of head and neck injuries in international football. Br J Sports Med 2005;XX(suppl x):xxx-xxx.

14 Fuller C, Smith G, Junge A, et al. An assessment of player error as an injury causation factor in international football. Am J Sports Med 2004;32:28S-32S.

15 Fuller C, Junge A, Dvorak J. An assessment of football referees' decisions in incidents leading to player injuries. Am J Sports Med 2004;32:17S-22S

16 Fuller C, Hawkins R. Assessment of football grounds for player safety. Saf Sci 1997; 27:115-28.

17 Hawkins R, Fuller $C$. An examination of the frequency and severity of injuries and incidents at three levels of professional football. Br J Sports Med 1998:32:326-32.

18 Rahnama N, Reilly T, Lees A. Injury risk associated with playing actions during competitive soccer. Br J Sports Med 2002;36:354-9.

19 Andersen TE, Larsen O, Tenga A, et al. Football incident analysis: a new video based method to describe injury mechanisms in professional football. Br J Sports Med 2003:37:326-32.

20 Fuller C, Smith G, Junge A, et al. The influence of tackle parameters on the propensity for injury in international players. Am J Sports Med 2004;32:43S-53S.

21 Newman J, Beusenberg M, Fournier E, et al. A new biomechanical assessment of mild traumatic brain injury. Part I-Methodology. International Research Council on the Biomechanics of Impact; 23-24 September 1999; Barcelona, Spain.
22 Pellman E, Viano D, Tucker A, et al. Concussion in professional football: reconstruction of game impacts and injuries. Neurosurgery 2003;53:799-814

23 Newman J, Shewchenko N, Beusenberg M et al. Verification of biomechanical methods employed in a comprehensive study of mild traumatic brain injury and the effectiveness of american football helmets. J Biomech 2005 (in press).

24 DiMasi F. Transformation of the Nine-Accelerometer-Package (NAP) Data for Replicating Headpart Kinematics in Dynamic Loading. Washington, DC: National Highway Traffic Safety Administration, 1995.

25 SAE. Surface Vehicle Recommendation Practice J21 1-1, Instrumentation for Impact Test. Part 1-Electronic Instrumentation. In: SAE Handbook. Warrendale, PA: Society of Automotive Engineers, 1995.

26 Newman J, Shewchenko N, Welbourne E. A proposed new biomechanical head injury index assessment function-the maximum power index. 44th Stapp Car Crash Conference, SAE International, 6-8 November 2000, Atlanta, GA.

27 Newman J, Beusenberg M, Fournier E, et al. A new biomechanical assessment of mild traumatic brain injury. Part 2-results and conclusions. International Research Council on the Biomechanics of Impact, 20-22 September 2000, Montpellier, France.

28 Shewchenko N, Withnall C, Keown M, et al. Heading in football. Part 1: Development of biomechanical methods to investigate head response. Br J Sports Med 2005;39(suppl I):i10-i25.

29 Mertz H. Injury risk assessments based on dummy responses. In: Accidental Injury Biomechanics and Prevention, 2nd edn. New York: Springer-Verlag, 2002.

30 Mertz H. Anthropomorphic test devices. In: Nahum A, Melvin J (eds) Accidental Injury Biomechanics and Prevention, 2nd edn. New York: Springer-Verlag, 2002. 